\title{
O dístico elegíaco latino em português: uma proposta de tradução
}

\author{
Rafael Sento-Sé Guimarães Falcón
}

\section{Introdução}

Fazemos neste artigo uma proposta de tradução do dístico elegíaco latino. Para tanto, além de expor certos princípios teóricos, demonstraremos alguns dos possíveis resultados práticos desses princípios, usando como amostra a elegia I, 9 de Propércio, reproduzida a seguir com a respectiva tradução.

Sexto Propércio foi um poeta romano do círculo de Mecenas, em que convivia com homens como Virgílio e Horácio. Sua poesia é musical e suave, própria para a recitação porque agradável aos ouvidos, tanto no som como no sentido. Não obstante, Propércio impressiona ainda mais por sua habilidade de usar uma palavra para expandir o sentido de outra. Por isso Ezra Pound considerou-o um mestre da logopéia, a "dança do intelecto entre as palavras". Sendo poeta elegíaco, Propércio limou a forma do dístico rumo à perfeição, como se verá adiante. 
Rafael Sento-Sé Guimarães Falcón. O dístico elegíaco latino em português: ...

Dicebam tibi uenturos, irrisor, amores, nec tibi perpetuo libera uerba fore:

ecce iaces supplexque uenis ad iura puellae, et tibi nunc quaeuis imperat empta modo.

non me Chaoniae uincant in amore columbae

dicere, quos iuuenes quaeque puella domet.

me dolor et lacrimae merito fecere peritum:

atque utinam posito dicar amore rudis!

quid tibi nunc misero prodest graue dicere carmen

aut Amphioniae moenia flere lyrae?

plus in amore ualet Mimnermi uersus Homero:

carmina mansuetus lenia quaerit Amor.

i quaeso et tristis istos sepone libellos,

et cane quod quaeuis nosse puella uelit!

quid si non esset facilis tibi copia! nunc tu

insanus medio flumine quaeris aquam.

necdum etiam palles, uero nec tangeris igni:

haec est uenturi prima fauilla mali

tum magis Armenias cupies accedere tigres

et magis infernae uincula nosse rotae,

quam pueri totiens arcum sentire medullis

et nihil iratae posse negare tuae.

nullus Amor cuiquam facilis ita praebuit alas,

ut non alterna presserit ille manu.

nec te decipiat, quod sit satis illa parata:

acrius illa subit, Pontice, se qua tuast,

quippe ubi non liceat uacuos seducere ocellos,

nec uigilare alio limine cedat Amor.

qui non ante patet, donec manus attigit ossa:

quisquis es, assiduas tu fuge blanditias!

illis et silices et possint cedere quercus, nedum tu possis, spiritus iste leuis.

quare, si pudor est, quam primum errata fatere:

dicere quo pereas saepe in amore leuat. 
Eu disse, zombador; "Terás amores!

Nem te há de ser a boca livre sempre!"

Pois eis que te ajoelhas às leis dela:

Comprada há pouco, já comanda a tudo.

Não vencem-me, no amor, pombas augúreas,

Se digo a quem, e qual menina doma.

Formaram-me perito a dor e os prantos;

(Quisera a todos ser no amor um néscio...!)

Agora de que serve um canto grave,

Chorar à lira de Anfião os muros?

Mimnermo é superior, no amor, a Homero;

O Amor é manso, e pede cantos dóceis.

Separa estes livrinhos tristes, anda!,

E canta o que elas querem, todas elas!

(Como se não tivesses tudo à mão...

És louco! Pedes água, em meio a um rio!)

Nem pálido... Nem foste chamuscado;

Sentiste só os sinais do mal vindouro.

Depois, preferirás tocar tigresas,

Sentir, da roda Inferior, grilhões,

Ao arco do Menino em tua espinha,

E, à tua irada, não negar-lhe nada.

O Amor não dá a ninguém asas propícias

Sem contra o chão prensá-lo co'outra mão.

E se ela estiver pronta, não te enganes;

Se é tua, aí machuca mais ainda.

Ah, sim!... Se desviar o olhar não podes,

Se o Amor não deixa velar noutro umbral...

Nunca o vemos... até que atinge os ossos.

Quem sejas, foge das branduras vãs!

Pois podem derrubar rocha e carvalho;

Que a ti fariam, pobre e frágil alma?

Assim, se tens pudor, assume os erros;

No amor, falar do que te aflige é bom. 
Rafael Sento-Sé Guimarães Falcón. O dístico elegíaco latino em português: ...

\section{Proposta de tradução do dístico elegíaco}

Nossa proposta é orientada por três objetivos principais, a saber:

a) clareza e familiaridade imediatas para o leitor leigo;

b) manutenção das imagens e tropos; e

c) reprodução, na medida do possível, do éthos do poeta.

Isso significa que, em primeiro lugar, desejamos evitar expressões que insinuem ao leitor uma necessidade intimidadora de estudo para ler a poesia latina; em segundo lugar, tentamos preservar aquelas figuras que revelam de modo mais ostensivo, principalmente para o leitor pouco familiarizado com os clássicos, o engenho do poeta; em terceiro lugar, importamo-nos com o aspecto subreptício da elocução de cada poeta, ou seja, o modo como procura caracterizar-se pela escolha léxica e pela sintaxe, que podem ser rústicas, elegantes ou arcaizantes, por exemplo. Numa palavra, trata-se de tradução que visa a divulgar a poesia latina para o público não-especialista.

Seguindo essa orientação, concebemos nossa proposta em pelo menos três dimensões, que pedimos emprestadas à terminologia da retórica: as figuras de palavras, as figuras de construção e o gênero (formato determinado por regras pré-existentes). É por meio dessa divisão que exporemos, uma por uma, as principais opções de tradução que concebemos e aplicamos à elegia I, 9.

\section{Figuras de palavras}

Trata-se dos chamados tropos, metáforas, imagens e articulações semânticas em geral. Nesse plano, nosso desafio é manter com o máximo de fidelidade as invenções, isto é, os achados do poeta, sem permitir que gerem estranheza capaz de intimidar. Idealmente, 
diríamos, a proposta é produzir um grau de especificidade que gere encanto pelo desconhecido, e não horror.

Há pelo menos um procedimento na tradução da elegia I, 9 que demonstra esse princípio: a omissão da referência geográfica no verso 5 (Chaoniae), substituída por "augúreas". É que tentamos suscitar um pensamento próximo ao do original, em que o poeta se referia às sacerdotisas caônias de Zeus (chamadas "pombas"), capazes de adivinhar o futuro; ora, aos olhos do leitor comum de hoje, a Caônia não desperta nenhuma relação com adivinhação, o que truncaria o entendimento imediato do verso seguinte (Propércio adivinha o futuro no amor, melhor que as sacerdotisas) que, em absoluto, nada tinha de obscuro para um romano. Sabe-se também que na Antigüidade os pássaros podiam ser observados com o intuito de prever o futuro; eis uma possível leitura, que as pombas da Caônia fossem de alguma maneira "instrumentos" mais exatos que as dos demais lugares. A ambigüidade, se houver, fica mantida pela preservação da palavra "pombas", embora não seja negada ao leitor uma compreensão razoável e imediata do que Propércio quer dizer com a comparação.

Ora, teremos um problema se considerarmos que Propércio queria, conforme prescrições de Calímaco, mostrar certo conhecimento geográfico ou etnológico. Mas essa é nossa opção de tradução: sacrificar um pouco do éthos properciano, talvez, mas em benefício de um efeito imediato mais eficaz, sem o que o poema não soaria culto, porém pedante. Não obstante, preservamos, por exemplo, a "lira de Anfião" (v. 10), por entender que se trata - agora sim - de alusão culta que permite deleite a partir da emulação. Perceba-se aí nossa distinção entre alusões sem significado para o leitor (que por isso podem parecer pedantismo) e a referência mítico-poética à lira de Anfião (que, como cremos, deveria atingir somente o romano educado, assim como nossa tradução atingirá o leitor instruído). No mais, procuramos sempre ressaltar o que não fosse tão óbvio para o leitor comum, como no verso 21, em que uma simples maiúscula na inicial de "menino" já indica, como pensamos, que se trata de Cupido. 
Rafael Sento-Sé Guimarães Falcón. O dístico elegíaco latino em português: ...

\section{Figuras de construção}

Reproduzimos as figuras de construção somente quando acrescentavam algo ao sentido imediato do poema ou, na melhor das hipóteses, quando não atrapalhavam outros aspectos da tradução. Em suma: consideramos os efeitos sonoros e gráficos de cada verso importantes, mas secundários se comparados a outros aspectos como a exatidão e a elocução familiar que aproxime autor e leitor.

O verso 4 é um bom exemplo das figuras que, construídas a partir de associações sonoras e gráficas, consideramos essenciais para o sentido. No original, estão juntas as palavras imperat ("ordena", "governa") e empta ("tendo sido comprada" ou simplesmente "comprada"). Ora, a evidente paronímia, isto é, a semelhança fônica e gráfica entre essas palavras, somada à proximidade no sintagma, sublinha a relação entre elas, que só pode ser de oposição. De fato, uma escrava não pode comandar, pois ela é por definição comandada. O fenômeno só pode ser explicado como efeito do Amor, que transforma, como sabem os leitores de elegias, o amante em escravo da amada. Habilmente, Propércio aproveita o tópico do seruitium amoris (escravidão infligida pelo amor), mostrando que ele pode mudar as regras da sociedade e forçar o senhor a servir sua escrava.

Na tradução, fomos impedidos de colocar próximas as duas palavras, por causa da métrica, que discutiremos mais à frente. Por isso, optamos por criar uma pausa sintática no meio do verso, que amplificasse a antítese, e separamos simetricamente as palavras e seus complementos: "Comprada há pouco, já comanda a tudo". A paronímia foi mantida, tendo em vista que apenas duas consoantes (-p e -r) e uma nasalização da vogal (-a-) diferenciam as palavras. Além disso, usamos economicamente a locução "há pouco", que estabelece oposição temporal com "já" e, por outro lado, faz ecoar uma oposição quantitativa entre "pouco" e "tudo". Cremos assim ter destacado, como Propércio, a absurdidade da situação de Pôntico. 


\section{Gênero}

O gênero elegíaco tem merecido numerosas discussões nas últimas décadas, principalmente porque a academia percebeu que há muito tempo ele não existe mais. É que os poemas que chamamos "elegias" recebem esse nome em geral pelos afetos ou pela matéria, e são considerados parte do gênero lírico, que abarcaria a elegia na qualidade de subgênero. Por outro lado, na Antigüidade, a elegia constituiu gênero particular, sobretudo pelo metro, o dístico elegíaco, que é sempre o mesmo.

Assim, na qualidade de tradutor, cabe-nos fazer o leitor perceber que está lidando com uma forma fixa, e com certa familiaridade que lhe permita sentir como aquela forma é adequada ao tema. Ora, o dístico elegíaco não tem correspondente em português, nem mesmo entre os classicistas e os árcades; para reproduzi-lo em nossa língua, teríamos que utilizar metros usados também na lírica, o que tiraria sua especificidade, ou inventar novo metro, o que causaria estranheza e dificultaria a fruição do poema. Não desejando incorrer em nenhum dos dois crimes, fizemos as duas coisas ao mesmo tempo.

Os poetas elegíacos romanos opunham-se conscientemente à épica, o que se verifica nas muitas elegias programáticas em que aparece o tema da recusatio. Por meio dessa oposição, foi possível dar um significado ao dístico elegíaco, que era formado por dois versos em metro épico (hexâmetro dactílico), sendo que o segundo verso de cada dístico tinha dois pés quebrados (hexâmetro duplamente cataléctico). Na interpretação dos romanos, era como se o dístico começasse prometendo um poema elevado, por causa do metro épico, mas quebrasse a promessa no segundo verso, ao desfazer o ritmo grave. Veja-se Ovídio: 
Rafael Sento-Sé Guimarães Falcón. O dístico elegíaco latino em português: ...

Arma graui numero uiolentaque bella parabam edere, materia conueniente modis.

Par est inferior uersus; risisse Cupido

dicitur atque unum surrupuisse pedem.

Armas em ritmo grave e violentas guerras eu me preparava para cantar, com uma matéria conveniente ao metro.

$\mathrm{O}$ verso de baixo era igual; Cupido riu, conta-se, e surrupiou um pé.

A lógica é implacável: ele pretendia escrever um poema em que a matéria fosse adequada ao metro; começou a fazer um poema épico, mas no segundo verso o metro mudou e, conseqüentemente, a matéria adequada já é outra. Dessa maneira, o tema amoroso parece ser forçosamente elegíaco, por exigência do metro, que pede afetos intermediários, entre os elevados e os médios. O dístico consiste numa promessa de elevação, seguida de uma frustração; o amor é exatamente a mesma coisa, pelo menos segundo Propércio (que talvez esteja falando, ambiguamente, também do dístico):

O Amor não dá a ninguém asas propícias

Sem contra o chão prensá-lo co'outra mão.

Por isso, tentamos provocar algo semelhante à sensação que os romanos tinham quando ouviam o dístico elegíaco, ou seja: uma expectativa de elevação, seguida da quebra dessa expectativa por um afeto "médio". Os leitores de nossa língua estão habituados ao decassílabo heróico como anunciador da elevação, e ao decassílabo sáfico como verso de afetos e elocução propriamente líricos: é dizer, médios. Ora, juntando os dois num só dístico, a sugestão resultante parece-nos não ser épica nem lírica; nem elevada nem exatamente média; eis um afeto e a respectiva elocução que poderiam ser da nossa "elegia portuguesa". 
A elegia amorosa romana também pode ser reconhecida pelo tema, tópicos, imagens, termos técnicos. Desses aspectos, preservamos tudo o que foi possível, colocando em primeiro lugar sempre o sentido imediato, mas aproveitando todas as oportunidades de preservar também o mais profundo, estrutural, que muitas vezes envolve negociações do poeta com os tipos e os termos do gênero em que escreve.

O estudioso notará a omissão dos termos técnicos puella (v. 3 e 14) e iuuenes (v. 6), por exemplo, bem como a indiferença da tradução ante o termo leuis (traduzido para "frágil"), no verso 32, e seu parônomo, leuat, dois versos depois, traduzido pela perífrase "é bom". Questões de métrica levaram-nos, talvez, a não optar pela palavra mais adequada tecnicamente e, assim, fazer o leitor perder o jogo estrutural que existe entre os versos 32 e 34 . São essas infelicidades, bem como outras que não mencionamos, que esperamos ter compensado, para o leitor, com a elocução familiar e clara da tradução, sem ambigüidades a não ser as do próprio poeta.

Ainda assim, e apesar da nossa proposta não ser voltada para o estudo acadêmico, procuramos manter imagens e termos técnicos quando julgamos que isso não faria mal a nosso público-alvo. $\mathrm{O}$ mesmo estudioso que notou nossos deslizes técnicos há de perceber a manutenção dos jogos com os tópoi do gênero elegíaco (como no v. 16, quando Pôntico ganha a chance de ser um "bebedor de água", por estar no meio de um rio, ou no v. 28, em que se faz referência ao lugar-comum de permanecer acordado à soleira da porta). O leitor despreocupado passará direto por esses cuidados, mas aquele um pouco mais versado não deixará de admirar-se com o engenho de Propércio; notará, de fato, que o poeta produzia não apenas belos efeitos imediatos, mas também engenhosas relações estruturais. 